Unless otherwise noted, the publisher, which is the American Speech-Language Hearing Association (ASHA), holds the copyright on all materials published in Perspectives on Voice and Voice Disorders, both as a compilation and as individual articles. Please see Rights and Permissions for terms and conditions of use of Perspectives content: http://journals.asha.org/perspectives/terms.dtl

\title{
From Reactive Intervention to Proactive Prevention: The Evolution of Occupational Dysphonia
}

Ruth Epstein

Royal National Throat Nose \& Ear Hospital and Ear Institute, University College

London, UK

Angélique Remacle

University of Liège

Liège, Belgium

Dominique Morsomme

University of Liège and University Hospital of Liège

Liège, Belgium

\begin{abstract}
Voice clinicians long have been aware of the concept of professional voice users: individuals who work in professions that have a higher incidence and increased risk for voice disorders. This realization, coupled with the documented impact of work-related dysphonia on the economy, has resulted in a growing international interest in developing occupational health benchmarks for voice use, similar to other standards developed for work-related factors such as noise-induced hearing loss. In this article, we review current perspectives and examine some issues related to occupational vocal health.
\end{abstract}

\section{Definition of Occupational Dysphonia}

One of the current challenges facing health practitioners is related to the definition of occupational voice disorders and the question of how vocal loading, incurred during occupational voice use, relates to vocal injury. Vocal loading is a term used to quantify the demands placed on the vocal mechanism by the way the voice is used and the extent to which it is used (Hunter \& Titze, 2010; Vilkman, 2004). Occupational disorders can be defined as diseases caused by exposure at work (Lehto, Laaksonen, Vilkman, \& Alku, 2006). People who use their voices professionally are at risk from occupational voice disorders. Risk factors for these individuals include high vocal load, background noise, poor room acoustics, dry and dusty air quality, and poor posture. Laryngeal injuries caused by high vocal loading can lead to absence at work or cancelled performances, lost income, prolonged rehabilitation periods, and in extreme cases, change of profession or early retirement. Occupational voice problems are not life threatening, but may cause physical discomfort and psychosocial stress (Vilkman).

Carroll and colleagues (2006) defined occupational voice users, such as teachers and daycare workers, as those "who, due to the vocal demands of their work and acoustically poor environments, injure their voices or acquire compensatory habits" (p. 595). In a book published following the 3rd Pan European Voice Conference in 1999, Dejonckere (2001) wrote in reference to occupational voice users "the pathogenesis of voice disorders in such patients can be primarily related to their occupation, and thus, after adequate differential diagnosis, these 
need to be recognised as true occupational diseases, in the same way as, for example, occupational hearing loss" (p. vii). Dejonckere also acknowledged that noise-induced hearing loss may be considered a useful comparative model for occupational voice disorders in some, but not all aspects. The obvious difference is that for hearing loss, the causative relationship between the intensity dose of noise exposure and its effect on hearing is clearly established (ISO-International Organisation of Standardization), whereas in the case of occupational dysphonia, it is yet to be proven. Dejonckere stressed the importance of the concept of dosimetry, which in the context of noise-induced hearing impairment combines intensity and duration. Other factors which should be contemplated when considering occupational voice disorders are the definition of safe limits for noise exposure, as well as possible preventive measures. That is, one should consider safe limits for vocal loading as well as prevention for occupational dysphonia.

\section{Population at Risk}

In today's world, one-third of the workforce consists of individuals whose main working tool is the voice (Titze, Lemke, \& Montequin, 1997). In the United States, this accounts for nearly one-quarter of the workforce (Hunter \& Titze, 2010). Professional voice users' livelihoods depend partially or wholly on the ability to produce voice. This group includes teachers, ministers, sales clerks, telemarketers, telephone operators, actors, singers, radio/television announcers, and attorneys. Although vocal load, sophistication, and voice quality may vary, professional voice users share a dependence on vocal endurance. Their constant voice use, or the vocal load required occupationally, may lead to vocal difficulties.

Problems reported by professional voice users are varied and may include hoarseness, voice breaks, intermittent voice loss, and vocal fatigue. Related physical complaints include shortness of breath, throat dryness, throat discomfort and tightness, and effortful speaking. Chronic voice problems may result in laryngeal irritation and edema or in benign vocal fold lesions including vocal fold nodules, polyps, and hemorrhages (Dejonckere, 2001; Vilkman, 2004).

\section{Risk Factors}

While talking may not be avoidable in some jobs, damage to voice and soft tissues is preventable. Awareness of the following risk factors may help occupational voice users recognize key causes that can lead to occupational voice loss.

- The incidence of dysphonia is higher in women.

- Several studies show that voice disorders are more prominent in older teachers (Dauw, 2004; Roy et al., 2004; Russell, Oates, \& Greenwood, 1998; Smith, Kirchner, Taylor, Hoffman, \& Lemke, 1998; Thibeault, Merrill, Roy, Gray, \& Smith, 2004).

- Titze (1999) and Vilkman (1996) have shown that talking in a noisy environment where background noise level exceeds 40 decibels (dB) contributed to the development of voice disorders.

- Ambient noise prompts the speaker to increase the volume in order to be heard, which results in increased fundamental frequency (Gramming, Sundberg, Ternström, Leanderson, \& Perkins, 1988), known as the Lombard effect. Room acoustics must be taken into consideration. The noise generated by sliding furniture, air conditioning, fluorescent lighting, heating, ventilation and adjacent hallways will be reflected against the inner walls of the room. This reflection is referred to as reverberation time. Longer reverberation time would result in the speaker using higher volume, which influences vocal intensity. In France, the decree 
of April 25, 2003 limits reverberation time to between 0.6 and 1.2 seconds for a volume of 250 cubic meters (Journal Officiel de la République Française, 2006).

- Low humidity can lead to an increased risk of throat irritation.

- $\quad$ Stress

- Fatigue

- Poor posture

- Air quality: e.g., exposure to chalk dust or marker fumes for teachers

- Chemicals

- Work methods: e.g., long scripts for call center workers

- Strain injuries: e.g., the use of speech recognition software as a response to repetitive strain injury (RSI) may result in vocal strain

All of these factors should be considered as part of the employer's risk assessment, and reasonable practical measures should be taken to minimize these risks.

\section{Incidence, Prevalence, and Risk Factors}

To quantify the impact of voice disorders on the workplace, incidence and prevalence rates in the general population should be examined. Incidence figures for voice problems are variable. The variability is mainly due to the fact that studies differ with regard to which samples are investigated, what methods are used, and which variables are tested. Studies from the United States estimate that approximately $25 \%$ of the working population rely on their voice as a primary working tool (National Center for Voice and Speech (NCVS), 1993). Within the general population, $3 \%$ to $9 \%$ of people have complained of a voice disorder at any one time (Verdolini \& Ramig, 1998).

Two large studies, conducted in Sweden (Fritzell, 1996) and the United States (Titze et al., 1997), examined the relative frequency of voice professionals attending voice clinics compared to the general population. The assumption was that greater representation in clinical caseload meant a greater occupational risk of dysphonia. The overall results of the studies suggested higher frequency of voice disorders in singers, and that teachers were among the highest at-risk occupation of individuals attending the clinics. Data are not available for the United Kingdom (UK); however, it is not unreasonable to assume that the same proportion of UK workers are similarly dependent on their voice as a primary working tool (Williams \& Carding, 2005), with a parallel incidence rate of occupational dysphonia. Interestingly, voice disorders in the UK are not considered an occupational disease (Williams, 2003). In France, a study conducted by the Mutuelle Générale de l'Education Nationale (MGEN), an insurance company, showed the prevalence of voice disorders was 39\% of in a group of 10,288 employees, which included teachers, directors, and public office workers (Nerrière, Vercambre, Gilbert, \& Kovess-Masfety, 2009).

Several studies have established a link between type of occupation and the presence of voice disorders (Fritzell 1996; Smith, Gray, Dove, Kirchner, \& Heras, 1997; Smith, Kirchner, Taylor, Hoffman, \& Lemke, 1998; Titze et al., 1997; Verdolini \& Ramig, 2001; Vilkman, 1996, 2000). Voice problems occur most frequently in occupations involving heavy vocal load, which is associated with prolonged voice use, and aggravated by factors such as presence of background noise, poor room acoustics, and stress. Fritzell, Titze and colleagues, and Vilkman (2000) have identified singers, actors, teachers, sports teachers, military personnel, telephone operators, business professionals, travel agents, and sales professionals as at increased risk for occupational voice disorders. 
Some professions have been more thoroughly investigated than others. For example, Heidel and Togersen (1993) and Long, Williford, Olson, and Wolfe (1998) showed that aerobics instructors suffer from aphonia, sore throat, and hoarseness. The authors identified a multifactorial etiology for their voice disorders that included having to do a job requiring verbal instruction against background noise at the same time as performing strenuous exercises. Other factors included poor acoustics, hours worked, years of experience, and climate changes.

Self-reported voice problems in singers and singing teachers also have been described. Miller and Verdolini (1995) found that voice disorders were up to 4 times higher in this group than non-singers. Risk factors for singing teachers included a past history of voice problems and the use of dehydrating medications. Other influential factors were gender, age, and a history of reflux.

A number of studies have found that teachers have the highest incidence of voice disorders (Nerrière et al., 2009; Roy et al., 2004), and constitute the highest risk (Smith et al., 1997). In the United States, this group represents 3.3 million people or $4 \%$ of the workforce (Roy et al.). Publications over the past 20 years suggest that $20 \%$ of teachers suffer from voice disorders. The symptoms are multiple and appear to worsen with time (Dauw, 2004; Kooijman et al., 2005; Nerrière et al., 2009), with the most frequent symptoms including hoarseness, vocal fatigue and difficulty speaking softly (Smith et al.).

Overall, the quality of studies investigating the incidence, prevalence, and risk factors of voice disorders are highly variable. Consequently, caution is required in attributing voice disorders to occupations. Teachers have been identified as an occupational group potentially at risk for voice disorders. However, studies are rarely prospective, and many are without controls. Furthermore, as the causes of most voice disorders are multi-factorial, it is wrong at this stage to assume that certain jobs cause voice disorders. In addition to job-related factors such as work environment, job requirements, training, and vocal loading, the impact of personal factors such as mood states and coping needs to be considered. Further prospective controlled studies need to focus on measuring voice usage in the workplace to provide more robust evidence about the relationship between occupational tasks and voice disorders.

\section{Consequences of Occupational Voice Disorders}

Voice problems experienced by professional voice users may lead to problems for the employee as well as the employer. The consequences are vocal, professional, and socioeconomic. Employees may exhibit reduced productivity, decreased work quality, and restriction of daily activities and social function, with subsequent reduction in quality of life. Employees may miss work as a result of the voice problems, and may even consider switching careers (Laukannen, Ilomaki, Leppanen, \& Vilkman, 2008; Roy et al., 2004). All of these may in turn increase stress levels, resulting in deteriorated quality of life (Titze et al., 1997). Employers may see increases in absenteeism (Roy et al.) and employee turnover, as well as raised costs for substitute workers, medical treatment, and workers' compensation claims. The estimated impact of occupational voice disorders on the economy is a loss of 2.5 trillion dollars in the United States in 2001 (Verdolini \& Ramig, 2001), and 5 million pounds in the UK.

\section{The Way Forward}

Voice therapy from a speech-language pathologist may be required if a worker develops a voice disorder. However, other protection strategies need to be implemented to help prevent vocal fold damage potentially vulnerable populations.

\section{Identification}

The first step is to clearly identify the population troubled by occupational voice disorders, as well as other risk factors. Roy and colleagues (2004) found that women 40 to 59 
years old with a 16-year teaching career and a family history of dysphonia were among those with the highest risk of developing an occupational voice disorder. Villanueva-Reyes (2011) corroborated these findings. In his study, $81 \%$ of subjects suffering from vocal problems were women whose average age was 43 years. The complaint most frequently encountered was vocal overuse (in $30 \%$ of cases), and working in a dusty environment. Similarly, Kosztyla-Hojna, Rogowski, Ruczaj, Pepinski, and Lobaczuk-Sitnik (2004) found that primary school teachers with an average age of 43 years represented the most prominent group of professional voice users with occupational dysphonia. Knowledge of the risk factors is crucial to accurate identification.

\section{Measuring Vocal Loading in the Workplace}

Dosimetry, or voice accumulation, is a system that can be used to objectify vocal behavior in an environmental setting. Different types of devices are currently available in this emerging market (e.g., Kay Pentax Ambulatory Phonation Monitor, Model 3200), and are beginning to be used in research studies (Hillman, Heaton, Masaki, Zeitels, \& Cheyne, 2006). These portable devices measure phonation duration, vocal intensity, and mean fundamental frequency. Data are extracted several times per second using an accelerometer attached to the neck and connected to a microprocessor storing data collected throughout the day. The data then are downloaded onto a computer for analyses, using specially designed software. Some dosimeters such as the VoxLog (Sonvox) have a microphone for measuring the ambient noise. Other individual factors that may influence coping with vocal workload are gender, endurance, health conditions, life habits, vocal skills, and experience, as well as psychosocial and personality factors (Williams \& Carding, 2005). Several studies currently are underway that aim to measure vocal load in different groups of occupational voice users in terms of duration, intensity, and frequency of phonation. These studies eventually will help clinicians understand the impact of vocal load and the risk factors in voice professionals. The outcome eventually will help clinicians establish a benchmark beyond which the risk is increased.

\section{Prevention}

Despite growing evidence of the incidence of dysphonia among occupational voice users, initiatives to prevent occurrence are sporadic. Preventative initiatives may include reduction of vocal intensity and duration of voice use and working towards improvement of building insulation. Using materials with better absorption and insulation qualities, particularly in public buildings, can reduce sound pressure level. Speakers should be encouraged to use voice amplifiers with light and flexible headsets. Reduction of vocal load can be addressed further by managing speaking time and vocal downtime ratio. Further studies are required to work out the recommended ratio in line with current research evidence.

Other strategies to help prevent voice disorders relate to building standards. Designs should be focused towards decreasing environmental noise effectively, particularly in educational institutions. Principal factors that need to be considered are reverberation time and absorption. Technical advancements in the construction industry have evolved to allow the implementation of these factors albeit at high cost. Compared to the loss to the economy generated by occupational voice disorders, however, this would be a worthwhile consideration.

\section{Education}

Information and training on how to manage the causes of voice problems in terms of voice care are generally considered to be beneficial in helping professionals avoid voice problems (Mattiske, Oates, \& Greenwood, 1998; Williams \& Carding, 2005). As advocated by Villanueva-Reyes (2011), the training should include both clinical and academic resources. The voice care model for teachers and teachers' college students used in Poland is another example of a proactive system that could be used to manage and prevent voice disorders in occupational voice users (Sliwinska-Kowalska et al., 2006). 


\section{Summary}

The importance of occupational vocal health is growing in recognition as more people rely on their voices for work. Further research on occupational dysphonia needs to be based in the workplace. The aims of this research should be to clarify the role of daily use in the causation of voice disorders, as well as to provide objective information about "normal limits" for voice use. Only with this information can we better serve individuals both at risk for voice disorders, as well as those who experience occupational dysphonia.

\section{References}

Aronsson, C., Bohman, M., Ternstrom, S., \& Sodersten, M. (2007). Loud voice during environmental noise exposure in patients with vocal nodules. Logopedics Phoniatrics Vocology, 32(2), 60-70.

Buekers, R., Bierens, E., Kingma, H., \& Marres, E. H. (1995). Vocal load as measured by the voice accumulator. Folia Phoniatrica et Logopedica, 47(5), 252-261.

Carroll, T., Nix, J., Hunter, E., Emerich, K., Titze, I., \& Abaza, M. (2006). Objective measurement of vocal fatigue in classical singers: A vocal dosimetry pilot study. Otolaryngology-Head and Neck Surgery, 135(4), 595-602.

Chang, A., \& Karnell, M. P. (2004). Perceived phonatory effort and phonation threshold pressure across a prolonged voice loading task: A study of vocal fatigue. Journal of Voice, 18(4), 454-466.

Chen, S. H., Chiang, S. C., Chung, Y. M., Hsiao, L. C., \& Hsiao, T. Y. (2010). Risk factors and effects of voice problems for teachers. Journal of Voice, 24(2), 183-190.

Dauw, S. (2004). Mate van (subjectieve) stemeleving bij leerkrachten uit het basisonderwijs gemeten a.d.h.v. de VHI en in het bijzonder bij leerkrachten uit de bovenbouw (Unpublished bachelor's thesis, Lessius Hoogeschool, Anterwerp, Belgium).

Dejonckere, P. H. (2001). Introduction: The concept of occupational voice disorders. In P. H. Dejonckere (Ed.), Occupational voice: Care and cure (pp. 7-12). The Hague, NED: Kugler.

Fritzell, B.-R. (1996). Voice disorders and occupations. Logopedics Phoniatrics Vocology, 21(1), 7-12.

Gramming, P., Sundberg, J., Ternström, S., Leanderson, R., \& Perkins, W. H. (1988). Relationship between changes in voice pitch and loudness. Journal of Voice, 2(2), 118-126.

Heidel, S. E., \& Togerson, J. K. (1993). Vocal problems among aerobic instructors and aerobic participants. Journal of Communication Disorders, 26, 179-191.

Hillman, R. E., Heaton, J. T., Masaki, A., Zeitels, S. M., \& Cheyne, H. A. (2006). Ambulatory monitoring of disordered voices. Annals of Otology, Rhinology and Laryngology, 115(11), 795-801.

Hunter, E. J., \& Titze, I. R. (2010). Variations in intensity, fundamental frequency, and voicing for teachers in occupational versus nonoccupational settings. Journal of Speech, Language, and Hearing Research, 53(4), 862-875.

ISO-1999. Acoustics: Determination of occupational noise exposure and estimation of noise-induced hearing impairment. Geneva, Switzerland: International Organization of Standardization 1990.

Journal Officiel de la République Française. (2006, April 25). Arrêté du 25 avril 2006 relatif à la limitation du bruit dans les établissements d'enseignement (p. 9102). Retrieved from http://www.admi.net/jo/2003/09102.html

Kooijman, P. G. C., de Jong, F. I. C. R. S., Oudes, M. J., Huinck, W., van Acht, H., \& Graamans, K. (2005). Muscular tension and body posture in relation to voice handicap and voice quality in teachers with persistent voice complaints. Folia Phoniatrica et Logopaedica, 57(3), 134-147.

Kosztyla-Hojna, B., Rogowski, M., Ruczaj, J., Pepinski, W., \& Lobaczuk-Sitnik, A. (2004). An analysis of occupational dysphonia diagnosed in the North-East of Poland. International Journal of Occupational Medicine and Environmental Health, 17(2), 273-278.

Laukkanen, A. M., Ilomaki, I., Leppanen, K., \& Vilkman, E. (2008). Acoustic measures and self-reports of vocal fatigue by female teachers. Journal of Voice, 22(3), 283-289. 
Lehto, L., Laaksonen, L., Vilkman, E., \& Alku, P. (2006). Occupational voice complaints and objective acoustic measurements-do they correlate? Logopedics Phoniatrics Vocology, 31(4), 147-152.

Long, J., Williford, H. N., Olson, M. S., \& Wolfe, V. (1998). Voice problems and risk factors among aerobics instructors. Journal of Voice, 12(2), 197-207.

Masuda, T., Ikeda, Y., Manako, H., \& Komiyama, S. (1993). Analysis of vocal abuse: Fluctuations in phonation time and intensity in 4 groups of speakers. Acta Otolaryngol, 113(4), 547-552.

Mattiske, J. A., Oates, J. M., \& Greenwood, K. M. (1998). Vocal problems among teachers: A review of prevalence, causes, prevention, and treatment. Journal of Voice, 12(4), 489-499.

Miller, M. K., \& Verdolini, K. (1995). Frequency and risk factors for voice problems in teachers of singing and control subjects. Journal of Voice, 9(4), 348-362.

National Center for Voice \& Speech. Occupational and voice data. Iowa City, IA: National Center for Voice and Speech.

Nerrière, E., Vercambre, M.-N., Gilbert, F., \& Kovess-Masfety, V. (2009). Voice disorders and mental health in teachers: A cross-sectional nationwide study. BMC Public Health, 9, 370.

Ramig, L. O., \& Verdolini, K. (1998). Treatment efficacy: Voice disorders. Journal of Speech, Language, and Hearing Research, 41(1), S101-116.

Rantala, L., Vilkman, E., \& Bloigu, R. (2002). Voice changes during work: Subjective complaints and objective measurements for female primary and secondary schoolteachers. Journal of Voice, 16(3), 344355.

Roy, N., Merrill, R. M., Thibeault, S., Parsa, R. A., Gray, S. D., \& Smith, E. M. (2004). Prevalence of voice disorders in teachers and the general population. Journal of Speech, Language, and Hearing Research, 47(2), 281-293.

Russell, A., Oates, J., \& Greenwood, K. M. (1998). Prevalence of voice problems in teachers. Journal of Voice, 12(4), 467-479.

Sliwinska-Kowalska, M., Niebudek-Bogusz, E., Fiszer, M., Los-Spychalska, T., Kotylo, P., SznurowskaPrzygocka, B., et al. (2006). The prevalence and risk factors for occupational voice disorders in teachers. Folia Phoniatrica et Logopedica, 58(2), 85-101.

Smith, E., Gray, S. D., Dove, H., Kirchner, L., \& Heras, H. (1997). Frequency and effects of teachers' voice problems. Journal of Voice, 11(1), 81-87.

Smith, E., Kirchner, H. L., Taylor, M., Hoffman, H., \& Lemke, J. H. (1998). Voice problems among teachers: Differences by gender and teaching characteristics. Journal of Voice, 12(3), 328-334.

Smith, B. E., \& Kuehn, D. P. (2007). Speech evaluation of velopharyngeal dysfunction. Journal of Craniofacial Surgery, 18(2), 251-261.

Sodersten, M., Ternstrom, S., \& Bohman, M. (2005). Loud speech in realistic environmental noise: Phonetogram data, perceptual voice quality, subjective ratings, and gender differences in healthy speakers. Journal of Voice, 19(1), 29-46.

Szabo, A., Hammarberg, B., Granqvist, S., \& Sodersten, M. (2003). Methods to study pre-school teachers' voice at work: Simultaneous recordings with a voice accumulator and a DAT recorder. Logoped Phoniatr Vocol, 28(1), 29-39.

Thibeault, S. L., Merrill, R. M., Roy, N., Gray, S. D., \& Smith, E. M. (2004). Occupational risk factors associated with voice disorders among teachers. Annals of Epidemiology, 14(10), 786-792.

Titze, I. R. (1999). Toward occupational safety criteria for vocalization. Logopedics Phoniatrics Vocology, 24(2), 49-54.

Titze, I. R., Lemke, J., \& Montequin, D. (1997). Populations in the U.S. workforce who rely on voice as a primary tool of trade: a preliminary report. Journal of Voice, 11(3), 254-259.

Titze, I. R., Svec, J. G., \& Popolo, P. S. (2003). Vocal dose measures: Quantifying accumulated vibration exposure in vocal fold tissues. Journal of Speech, Language, and Hearing Research, 46(4), 919-932.

Verdolini, K., \& Ramig, L. O. (2001). Review: Occupational risks for voice problems. Logopedics Phoniatrics Vocology, 26(1), 37-46.

Vilkman, E. (1996). Occupational risk factors and voice disorders. Logopedics Phoniatrics Vocolology, 21(34), 137-141. 
Vilkman, E. (2000). Voice problems at work: A challenge for occupational safety and health arrangement. Folia Phoniatrica et Logopedica, 52(1-3), 120-125.

Vilkman, E. (2004). Occupational safety and health aspects of voice and speech professions. Folia Phoniatrica et Logopedica, 56(4), 220-253.

Villanueva-Reyes, A. (2011). Voice disorders in the metropolitan area of San Juan, Puerto Rico: Profiles of occupational groups. Journal of Voice, 25(1), 83-87.

Williams, N. R. (2003). Occupational groups at risk of voice disorders: A review of the literature. Occupational Medicine, 53(7), 456-460.

Williams, N., \& Carding, P. (2005). Occupational voice loss. Boca Raton, LA: Taylor and Francis. 